\title{
AuCu@Pt Nanoalloys for Catalytic Application in Reduction of 4-Nitrophenol
}

\author{
Sadia Mehmood, ${ }^{1}$ Naveed Kausar Janjua, ${ }^{1}$ Farhat Saira, ${ }^{1}$ and Hicham Fenniri ${ }^{2,3}$ \\ ${ }^{1}$ Department of Chemistry, Quaid-i-Azam University, Islamabad 45320, Pakistan \\ ${ }^{2}$ National Institute for Nanotechnology and Department of Chemistry, University of Alberta, \\ 11421 Saskatchewan Drive, Edmonton, AB, Canada T6G 2M9 \\ ${ }^{3}$ Department of Chemical Engineering, 313 Snell Engineering Center, 360 Huntington Avenue, Boston, MA 02115-5000, USA
}

Correspondence should be addressed to Naveed Kausar Janjua; nkausarjanjua@yahoo.com

Received 28 January 2016; Accepted 1 March 2016

Academic Editor: Rizwan Hasan Khan

Copyright (C) 2016 Sadia Mehmood et al. This is an open access article distributed under the Creative Commons Attribution License, which permits unrestricted use, distribution, and reproduction in any medium, provided the original work is properly cited.

To enhance and optimize nanocatalyst ability for nitrophenol (4-NP) reduction reaction we look beyond Au-metal nanoparticles and describe a new class of Au nanoalloys with controlled composition for core of AuCu-metals and Pt-metal shell. The reduction of 4-NP was investigated in aqueous media spectroscopically on $7.8 \mathrm{~nm}$ Au nanospheres (AuNSs), $8.3 \mathrm{~nm}$ AuCuNSs, and 9.1 nm AuCu@Pt core-shell NSs in diameter. The rate constants of the catalyzed reaction at room temperature, activation energies, and entropies of activation of reactions catalyzed by the AuCu@Pt core-shell NSs are found to have different values to those of the pure metal NSs. The results strongly support the proposal that catalysis by nanoparticles is taking place efficiently on the surface of NSs. These core-shell nanocatalysts exhibited stability throughout the reduction reaction and proved that heterogonous type mechanisms are most likely to be dominant in nanoalloy based catalysis if the surface of the NSs is not defected upon shell incorporation.

Dedicated to Professor Dr. Mathias Brust

\section{Introduction}

Versatile optical, chemical, and electronic properties of $\mathrm{Au}$ nanoparticles (AuNPs) have made them an attractive candidate in the field of sensing, biomedicine, electronics, imaging, and last but not least catalysis [1-5]. As a catalyst, the unique properties of nanomaterials catalyze different reaction types at much faster rates due to higher surface energies (because of unsaturated valencies of surface atoms of NPs) as compared to their respective bulk partners [6-10]. The key factors controlling the catalytic efficiency of the nanomaterials are shape, size, concentration, and temperature which have attracted intense attention over the past few years [6-9]. Reduction of 4-nitrophenol to 4-aminophenol in the presence of sodium borohydride $(\mathrm{BH})$ on the surface of nanoparticles as catalyst is one of the model catalytic reactions [11-14]. This model reaction has also been investigated on bimetallic nanoparticles during the last decade by many researchers due to additional degrees of freedom and versatility of compositions in bimetallic NPs [15-18].

Reduction of 4-nitrophenol (4-NP) to 4-aminophenol (4AP) was first identified by Pradhan et al. in the presence of catalyst [19]. 4-NP is an organic pollutant, found in industrial waste water, while 4-AP is a potent intermediate in the synthesis of many analgesics and fever reducing drugs, for example, phenacetin and paracetamol, are also used in industry as photographic developer, hair dyeing agent, and corrosion inhibitor [20,21]. Reduction of 4-NP by sodium borohydride $(\mathrm{BH})$ is thermodynamically feasible but without catalyst this reaction is not favorable [22]. This reaction proceeds in aqueous solution in the presence of either immobilized or free nanoparticles. UV-vis spectroscopy easily monitors the 
TABLE 1: Composition of synthesized AuCu alloys and their codes.

\begin{tabular}{lccc}
\hline $\mathrm{HAuCl}_{4} / \mathrm{Cu}(\mathrm{acac})_{2}$ molar ratio & $\mathrm{Au}($ atom \%) & $\mathrm{Cu}$ (atom \%) & Compositional codes \\
\hline $1 / 1$ & $50.09 \pm 0.6$ & $50.06 \pm 0.4$ & $\mathrm{Au}_{49} \mathrm{Cu}_{51}$ \\
$1 / 2$ & $33.94 \pm 0.6$ & $66.42 \pm 0.6$ & $\mathrm{Au}_{34} \mathrm{Cu}_{66}$ \\
$1 / 3$ & $28.76 \pm 0.4$ & $71.24 \pm 0.5$ & $\mathrm{Au}_{29} \mathrm{Cu}_{71}$ \\
$\mathbf{1} / \mathbf{2 0 . 3 4}$ & $6.25 \pm 0.2$ & $\mathbf{7 9 . 9 5} \mathbf{0 . 2}$ & $\mathrm{Au}_{20} \mathrm{Cu}_{\mathbf{8 0}}$ \\
$1 / 15$ & $5.27 \pm 0.5$ & $93.77 \pm 0.5$ & $\mathrm{Au}_{6} \mathrm{Cu}_{94}$ \\
$1 / 18$ & $3.23 \pm 0.6$ & $94.73 \pm 0.4$ & $\mathrm{Au}_{5} \mathrm{Cu}_{95}$ \\
$1 / 30$ & $2.46 \pm 0.6$ & $96.77 \pm 0.6$ & $\mathrm{Au}_{3} \mathrm{Cu}_{97}$ \\
$1 / 36$ & & $97.85 \pm 0.4$ & $\mathrm{Au}_{2} \mathrm{Cu}_{98}$ \\
\hline
\end{tabular}

reduction of this organic pollutant by the strong absorption of 4-nitrophenolate anion at $400 \mathrm{~nm}$. Spectrophotometric data also allows the calculation of the rate constant, activation energies, frequency factors, and entropy of activation for this reaction [23].

Reduction of 4-nitrophenol (4-NP) by BH is used as a model reaction for the catalytic evaluation of the synthesized nanomaterials [21, 22]. Many reports have come forward regarding the adsorption of 4-NP and $\mathrm{BH}$ on the surface of the AuNPs, following a simple Langmuir-Hinshelwood model $[20,21]$. In the present study as well, it was observed that $\mathrm{BH}$ adsorbs on the surface of AuNPs and $\mathrm{Au}$ alloys. This was monitored by a corresponding blue shift in the SPR (surface plasmon resonance) of AuNPs from 4 to $9 \mathrm{~nm}$, depending upon the $\mathrm{BH}$ concentration used $[22,23]$. The higher the $\mathrm{BH}$ concentration is, the more the SPR shift will be and the greater the conversion of 4-NP to 4-AP will be.

Gathering all the information mentioned above, there is a need for a kinetic model to explain the important findings for this reaction. The kinetic data was found to be best analyzed in terms of the Langmuir-Hinshelwood model [24]. Both the reactants $\mathrm{BH}$ and $4-\mathrm{NP}$ get adsorbed on the surface of nanoparticles during the course of reaction producing a Langmuir isotherm [25-30]. In the final step, the 4-AP is removed during the fast reaction.

\section{Materials and Methods}

2.1. Materials. Tetrachloroaurate trihydrate $\left(\mathrm{HAuCl}_{4} \cdot 3 \mathrm{H}_{2} \mathrm{O}\right.$, 99.9\%), oleylamine (technical grade, 70\%), methanol (98\%), and hexane (99\%) were purchased from Sigma Aldrich and used without any further purification. Sodium borohydride and 4-nitrophenol were purchased from Fluka. Double distilled water was used in all experiments.

2.2. Synthesis of $A u$ Nanospheres (AuNSs). Oleylamine (OAm) stabilized gold nanoparticles (AuNPs) of $7.8 \pm$ $1.5 \mathrm{~nm}$ diameters were synthesized using previously reported method [31]. According to this method, $50 \mathrm{mmol} \mathrm{HAuCl}_{4}$ was dissolved in $4.6 \mathrm{~mL}$ oleylamine $(70 \%) ; \mathrm{N}_{2}$ was blown for $10 \mathrm{~min}$ over reaction mixture to remove $\mathrm{O}_{2}$. Solution was heated to $160^{\circ} \mathrm{C}$; after $15 \mathrm{~min}$ of the reaction solution changed from orange to deep red indicating the reduction of $\mathrm{Au}^{3+}$ ions under stirring. Reaction was completed in $60 \mathrm{~min}$ indicated by change of $\mathrm{UV}$-vis profile for $\mathrm{Au}^{3+}$ to $\mathrm{Au}^{0}$. The solution was removed from stirring and cooled to room temperature without stopping the stirring and precipitated by adding methanol (Figure 1(a)).

2.3. Synthesis of AuCu Nanospheres (AuCuNSs). The synthesized AuNSs were used as seeds for fabrication of AuCuNSs alloy. A solution of $0.23 \mathrm{mM} \mathrm{C}_{10} \mathrm{H}_{14} \mathrm{CuO}_{4}\left(\mathrm{Cu}(\mathrm{acac})_{2}\right)$ in OAm was mixed with AuNSs solution in OAm and heated at $280^{\circ} \mathrm{C}$ for $30 \mathrm{~min}$ under nitrogen flow and rapid magnetic stirring. After cooling the $\mathrm{AuCu}$ sol to room temperature, methanol addition precipitated out the AuCuNSs. These NPs are dispersible in nonpolar solvent, like hexane. The atomic ratio of $\mathrm{Au} / \mathrm{Cu}$ was set as 1:4 by using precursors of appropriate molarity; hence the synthesized NSs were termed as $\mathrm{AuCu}_{4}$ (Table 1). Then all synthesized nanomaterials were phase transferred from organic to aqueous phase by utilizing protocol adopted by Gao et al. [32].

2.4. Synthesis of Core-Shell AuCu@Pt Nanospheres(AuCu@PtNSs). For already synthesized $\mathrm{AuCu}$ alloy, $\mathrm{Pt}$ shell was formed by adding $14.85 \mathrm{mg}$ of $\mathrm{C}_{10} \mathrm{H}_{14} \mathrm{PtO}_{4}$ dissolved in OAm and keeping temperature at $240^{\circ} \mathrm{C}$ under nitrogen flow with continuous stirring for $1 \mathrm{hr}$. The color of solution turned dark black in tone after $5 \mathrm{~min}$ of reaction under nitrogen flow. After $1 \mathrm{hr}$, the sol was cooled down to room temperature to precipitate AuCu@Pt nanoalloys by adding methanol (Figure 1(b)).

Before each catalytic experiment, these NSs were ultrasonicated for $15 \mathrm{~min}$. In a standard quartz cuvette $100 \mu \mathrm{L}$ of $10 \mathrm{nM}$ AuNPs was added followed by the addition of $100 \mu \mathrm{L}$ of $1 \mathrm{mM} 4$-NP solution. The total volume was adjusted to $3.5 \mathrm{~mL}$ with water and at the end a freshly prepared ice-cold $\mathrm{NaBH}_{4}(100 \mu \mathrm{L}$ of $100 \mathrm{mM})$ was added to the mixture of 4-nitrophenol and NSs. The light yellow color of the 4-nitrophenol became immediately yellowish green due to the formation of 4-nitrophenolate ion. The timedependent reduction was elucidated from the absorbance spectra which were recorded with a time interval of 1 to $5 \mathrm{~min}$. It was observed that the rate constant was increased with the amount of Au nanocatalyst, $\mathrm{BH}$ concentration, and temperature. Furthermore, the Au nanocatalyst was found to be quite stable with excellent catalytic ability. 


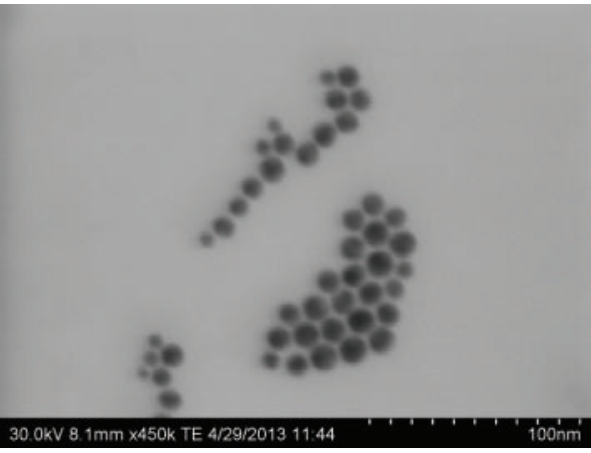

(a)

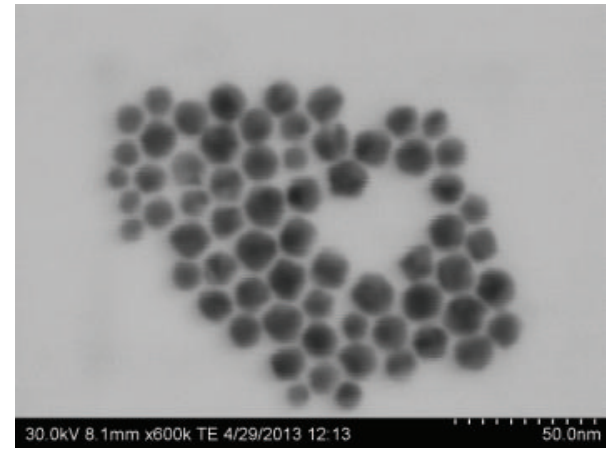

(b)

Figure 1: TEM of AuNSs (a) and AuCu@PtNSs (b).
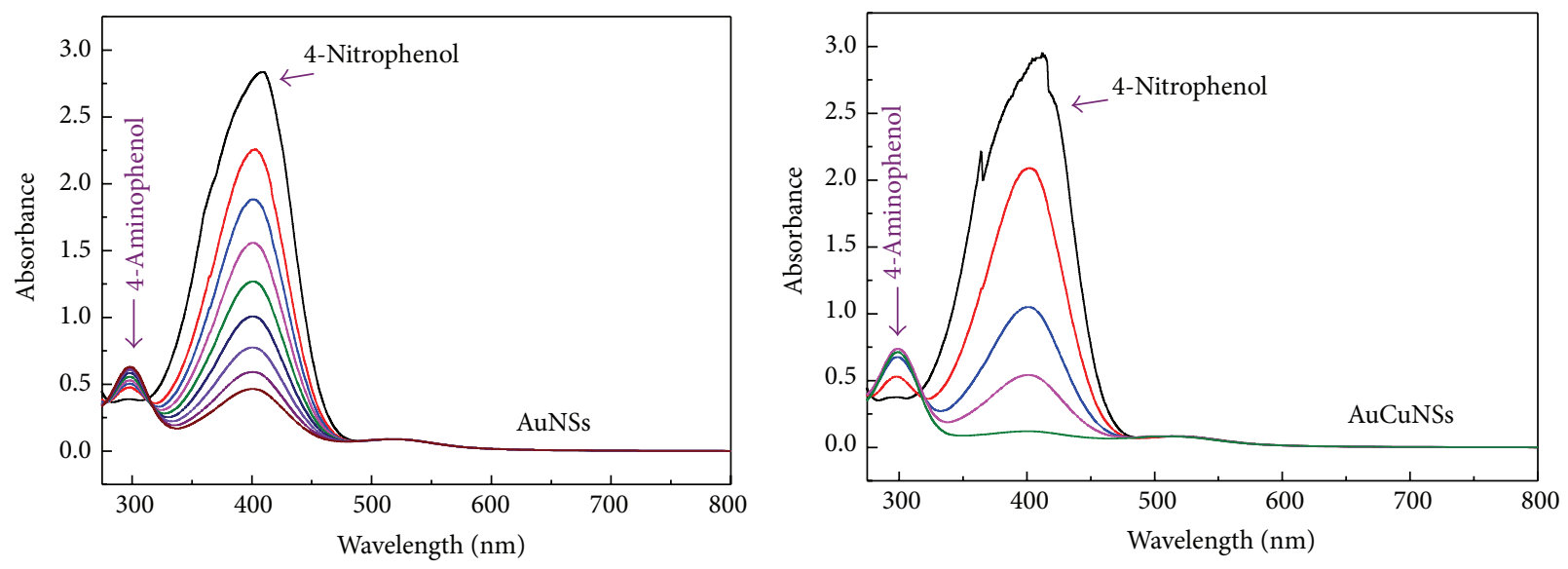

$\begin{array}{lll}\text { Time (min) } & & \\ -0 & 10 & -20 \\ -3 & -12 & -25 \\ 5 & 15 & -30\end{array}$

Time (min)

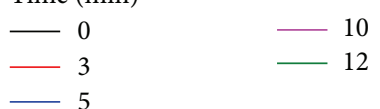

(a)

(b)

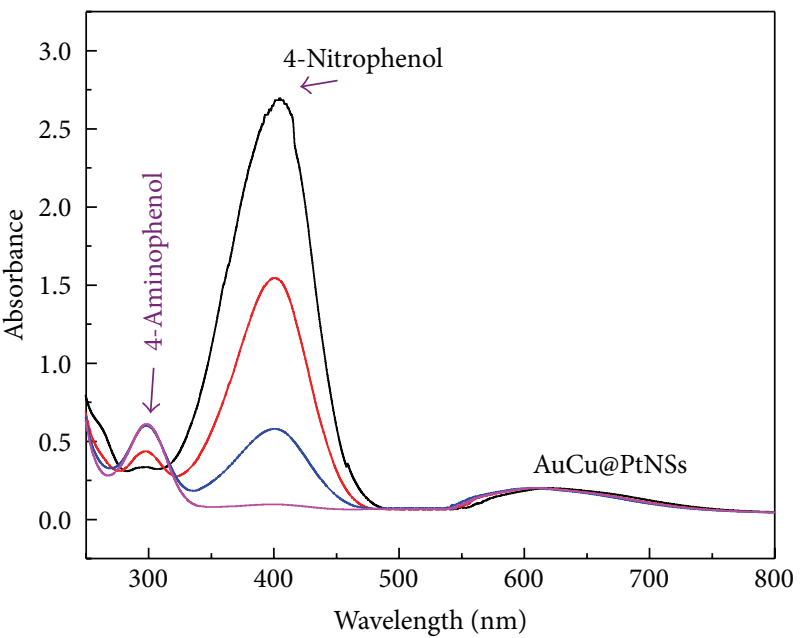

Time (min)

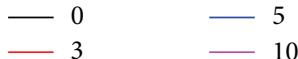

(c)

FIgURE 2: UV-visible spectra for catalytic reduction of 4-NP in the presence of AuNSs (a), AuCuNSs (b), and AuCu@PtNS (c). 

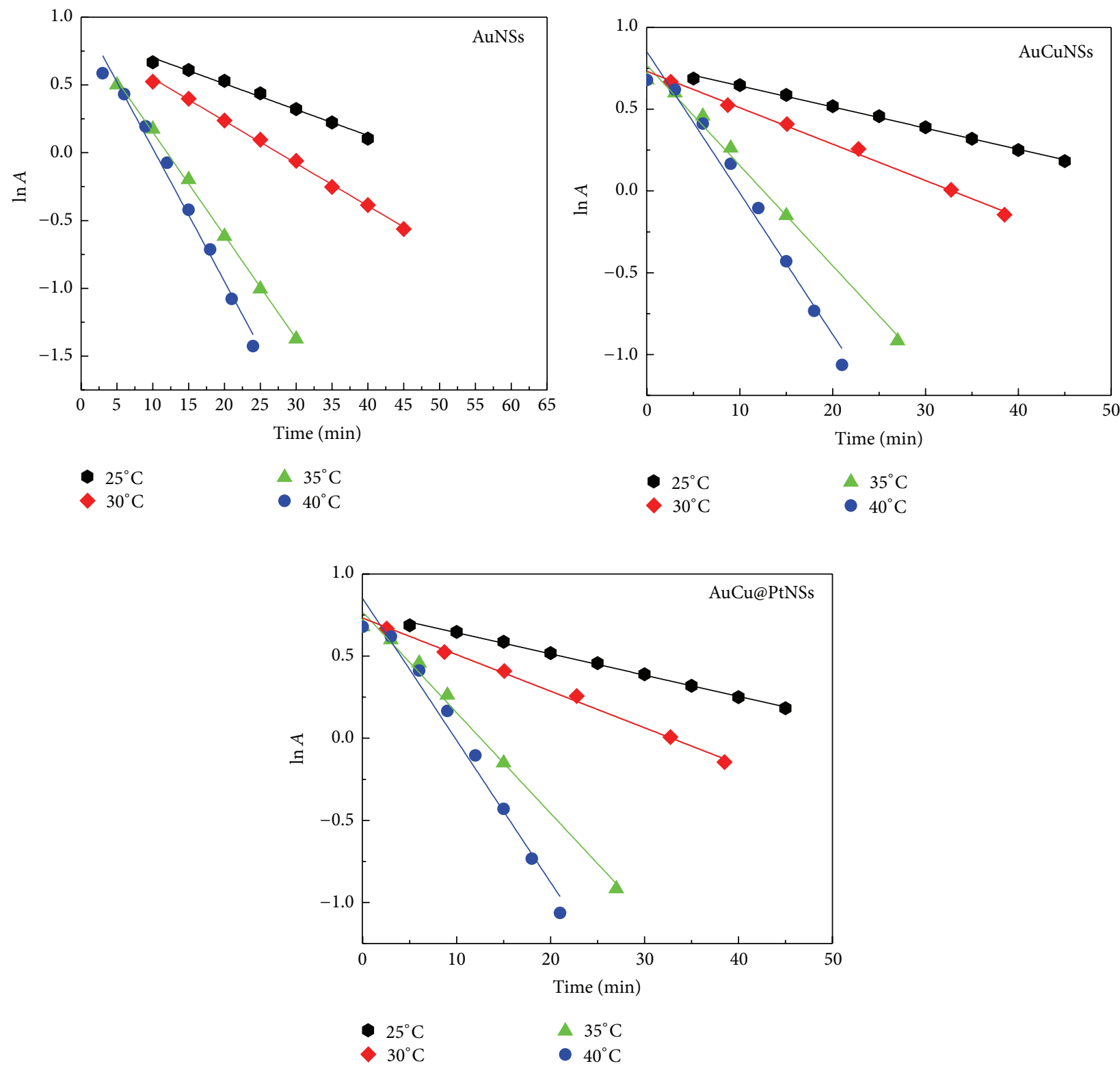

Figure 3: Kinetics of 4 -NP reduction process assisted by nanocatalysts at $25^{\circ} \mathrm{C}$ (black, hexagon), $30^{\circ} \mathrm{C}$ (red, diamond), $35^{\circ} \mathrm{C}$ (green, triangle), and $40^{\circ} \mathrm{C}$ (blue, sphere).

2.5. Characterization of NSs. TEM analyses were done using high resolution Hitachi S-4800 cold field emission SEM. All the catalytic and stability experiments were carried out on an Agilent 8453 UV-visible spectrophotometer at a wavelength range of $190-1100 \mathrm{~nm}$.

\section{Results and Discussion}

3.1. Catalytic Reduction of 4-Nitrophenol in the Presence of Au, $A u C u$, and AuCu@Pt Nanospheres (NSs). OAm stabilized AuNPs and Au alloys were prepared by Yang et al. method [33] and were further used for catalytic reduction of 4-NP. The stability and the extent of the catalytic activity of AuNPs were investigated in detail under several different chemical and physical conditions. Graphical abstract is the scheme of the AuNPs catalyzed reduction of 4-NP. SPR is highly sensitive to the chemical environment of the species surrounding the AuNPs; hence, activity of AuNPs was studied in terms of the SPR. There was no shift in SPR after adding 4-NP alone, but 4-NP immediately converts to 4-nitrophenolate ion and $\lambda_{\text {max }}$ shifted from $315 \mathrm{~nm}$ to $400 \mathrm{~nm}$ in the presence of AuNPs (Figure 2(a)). Thus, it is the 4-nitrophenolate ion that reduces to form aminophenol. This can be taken as an evidence that 4-NP has been adsorbed on the surface of the AuNPs.

Bimetallic nanoparticles are particularly useful due to versatile composition and structural variations that may be adjusted in order to improve catalytic behavior. Bimetallic catalysts frequently display catalytic activity that is higher than either constituent material for reduction of 4-NP [1517]. Accordingly, the reduction rates can be regarded as being 
TABLE 2: Comparison of rate constants of 4-nitrophenol reduction process in the presence of AuNSs, AuCuNSs, and AuCu@PtNSs at different temperatures.

\begin{tabular}{lccrc}
\hline Sample code & \multicolumn{4}{c}{ Rate constant $\left(\mathrm{min}^{-1}\right)$} \\
& $25^{\circ} \mathrm{C}$ & $30^{\circ} \mathrm{C}$ & $35^{\circ} \mathrm{C}$ & $40^{\circ} \mathrm{C}$ \\
\hline AuNSs & $0.009 \pm 0.0001$ & $0.019 \pm 0.0001$ & $0.04 \pm 0.002$ & $0.07 \pm 0.0002$ \\
AuCuNSs & $0.013 \pm 0.0001$ & $0.027 \pm 0.0002$ & $0.05 \pm 0.001$ & $0.095 \pm 0.0001$ \\
AuCu@PtNSs & $0.039 \pm 0.0002$ & $0.05 \pm 0.0009$ & $0.59 \pm 0.008$ & $0.099 \pm 0.0003$ \\
\hline
\end{tabular}

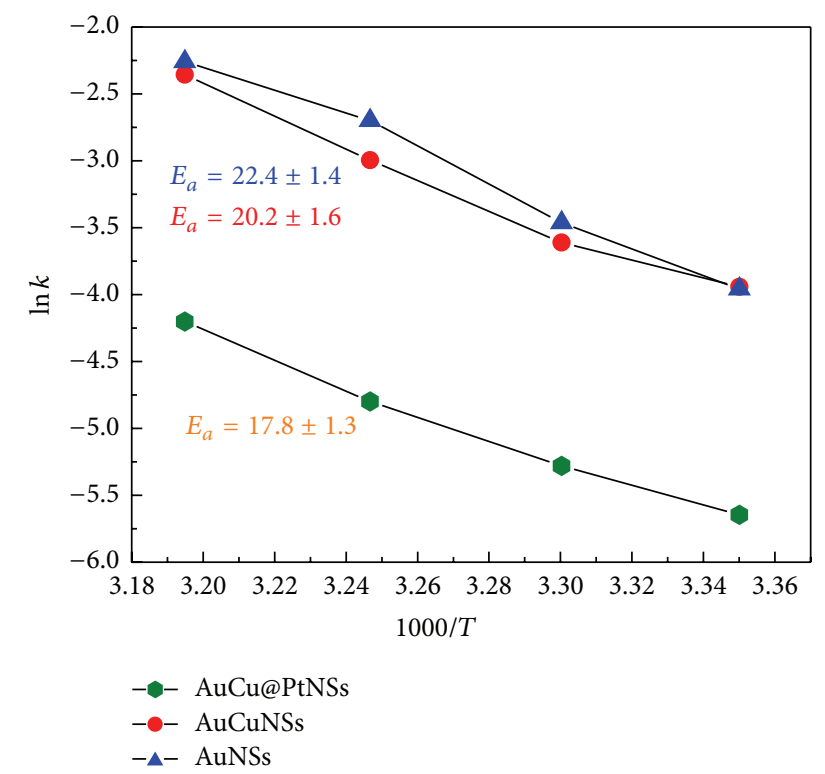

FIgURE 4: Arrhenius plots for the catalytic reduction of 4nitrophenol with $100 \mathrm{mM} \mathrm{BH}$ at temperatures of $25^{\circ} \mathrm{C}, 30^{\circ} \mathrm{C}, 35^{\circ} \mathrm{C}$, and $40^{\circ} \mathrm{C}$.

independent of the concentration of $\mathrm{NaBH}_{4}$. After adding $\mathrm{NaBH}_{4}$ into the aqueous solution of $4-\mathrm{NP}$, the color of the solution changed from light yellow to dark yellow due to the formation of 4-nitrophenolate ion. Then, the color of the 4-nitrophenolate ions faded with time after the addition of AuCuNSs. The progress of the reaction could be monitored by UV-vis spectroscopy. The characteristic peak of 4-NP at $400 \mathrm{~nm}$ decreased, while at $315 \mathrm{~nm}$ a new peak appeared which was assigned to 4-AP (Figure 2(b)) with the progress of reaction. The reaction was finished within $12 \mathrm{~min}$ at $25^{\circ} \mathrm{C}$. The reaction did not proceed in this period in the absence of AuCuNSs. In Figure 2(b), decrease in absorbance of 4-NP peak from a value of 2.13 to 0.12 in the presence of AuCuNSs is obvious within $15 \mathrm{~min}$ of the reaction time, which shows faster reaction kinetics than in the presence of AuNSs where a decrease in absorbance occurred in $30 \mathrm{~min}$ from a value of 2.8 to 0.35 .

The catalytic reduction of 4-NP is obvious in the presence of AuCu@PtNSs (Figure 2(c)). In this case, the decreasing trend in the peak value is observed at $400 \mathrm{~nm}$ and a new peak at 315 is indicative of 4-AP production as the result of reduction reaction [12-15]. Also the SPR of AuCu@Pt nanospheres in the range of $608-615 \mathrm{~nm}$ is present showing the stability of nanocatalyst even after the reaction is completed.
3.2. Kinetics of Reaction. Reaction follows pseudo first-order kinetics. To calculate the rate constants, different experiments by varying the reactant concentrations ratios were performed under pseudo first-order kinetics. The rate constant was evaluated by plotting $\ln A$ (where $A$ is the absorbance of 4nitrophenolate ion at any time $t$ ) versus time and the slope values of the straight lines estimate the rate constants

$$
\ln A=\ln A_{0}-k t,
$$

where $A$ is absorbance of $4-\mathrm{NP}, t$ is time, and $k$ is rate constant. Plotting $\ln A$ versus time in Figure 3, pseudo first-order rate constant values were obtained $[13,14]$ (also see Table 2 ). It was observed that the rate constant for the degradation of 4-NP was greater at higher temperatures, that is, $35^{\circ} \mathrm{C}$ and $40^{\circ} \mathrm{C}$, and also the core-shell AuCu@Pt nanocatalyst offered better values of rate constants owing to the synergistic effects of the core and shell strategy.

Reduction of 4-NP on AuNPs has been demonstrated to follow Langmuir-Hinshelwood mechanism statistics [34]. In this mechanism, both reactant molecules adsorb on the surface of NPs before undergoing the bimolecular reaction. When $\mathrm{NaBH}_{4}$ is in excess, the rate is controlled by the adsorption of 4-NP, only. In the case of bimetallic $\mathrm{AuCu}$ nanoalloys, adsorbed molecules may diffuse and desorb from the surface; therefore, at higher temperature rate of desorption of molecules is faster, resulting in a higher value of rate constant as compared to that of pure AuNSs [15].

Increase in the kinetic data is rapid for $30-35^{\circ} \mathrm{C}$ temperature range. It can be correlated with the fact that this reaction is most favorable at $30-35^{\circ} \mathrm{C}$ in the presence of AuCu@Pt nanocatalysts. This kind of result was also obtained in previous experiments for Pd nanoalloys for the same reaction [31].

The activation energy was calculated using Arrhenius equation [9]:

$$
\ln k=\ln k_{0}-\frac{E_{a}}{R T} .
$$

In this case, $\ln k$ (rate constant) were plotted against $1 / T$ (Kelvin); the frequency factor $k_{0}$ and $E_{a}$ were obtained from intercept and slope of straight line, respectively (Figure 4).

Previously oligomer functionalized AuNPs of almost the same diameter were subjected to 4 -NP reduction reaction under the same conditions as the current one [35]. A comparison of resultant data with current experiments has shown that rate constant of $2.32 \times 10^{-3} \mathrm{~s}^{-1}$ with oligomer functionalized AuNPs is increased to $9 \times 10^{-3} \mathrm{~s}^{-1}$ proving higher catalytic activity of currently synthesized Au nanocatalyst. 


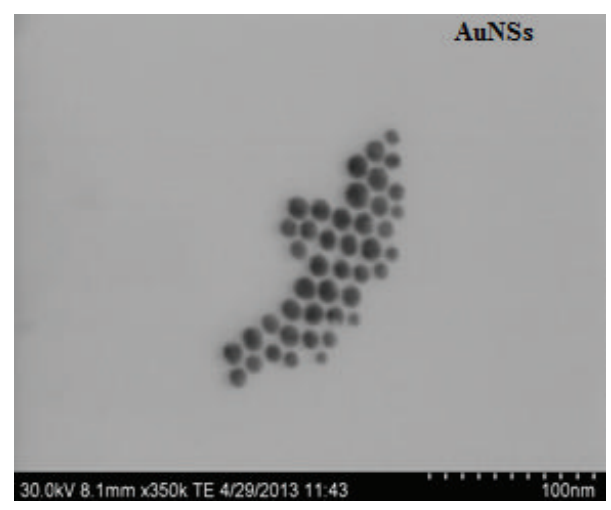

(a)

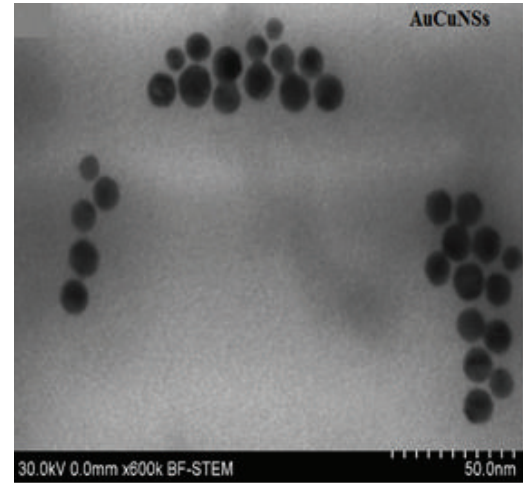

(b)

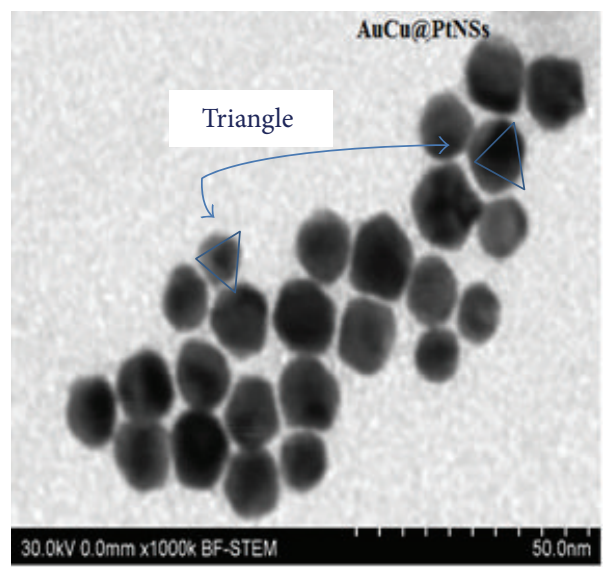

(c)

Figure 5: HRSEM for $\mathrm{Au}(\mathrm{a}), \mathrm{AuCu}(\mathrm{b})$, and $\mathrm{AuCu} @ \mathrm{Pt}$ (c) nanospheres.

\section{Conclusions}

In this study, the synthesized nanospheres of $\mathrm{Au}, \mathrm{AuCu}$, and AuCu@Pt were subjected to catalyzing the reduction reaction of 4-nitrophenol to aminophenol. The catalytic activities of $\mathrm{Au}, \mathrm{AuCu}$, and AuCu@PtNSs were compared for their rate of reduction of 4-NP. It was shown that AuCu@PtNSs were the most active catalyst for this reaction. This study has also elucidated a synergistic catalytic effect when $\mathrm{AuCu}$ is alloyed with a Pt shell for the reduction of 4-NP. The catalysis is attributed to the dominant behavior of the catalyst surface with bifunctional character with an electronically modified surface [36]. The temperature-dependent rate constant of this catalytic reduction reaction has been studied in the temperature range of $25-40^{\circ} \mathrm{C}$ and it was found that the rate of reduction was enhanced for AuCu@PtNSs at higher temperature, thus manifesting the stability of core-shell NSs.

It was anticipated that the reduction of 4-NP may have been controlled by the surface properties of the $\mathrm{Au}$ and its alloy nanoparticles. The morphological difference of the $\mathrm{Au}, \mathrm{AuCu}$, and $\mathrm{AuCu} @ \mathrm{Pt}$ nanospheres may pose different catalytic activities as has been observed for the 4-NP reduction; see the HRSEM shown in Figure 5 which are markedly different. The triangular shape indicates alloy core with a shell of Pt; both of these alloy core and monometallic shells are hence responsible for synergistic enhancement of catalytic reduction reaction (Figure 5).

\section{Competing Interests}

The authors declare that there are no competing interests regarding the publication of this paper.

\section{References}

[1] J. Han, Y. Liu, and R. Guo, "Facile synthesis of highly stable gold nanoparticles and their unexpected excellent catalytic activity for suzuki-miyaura cross-coupling reaction in water," Journal of the American Chemical Society, vol. 131, no. 6, pp. 2060-2061, 2009.

[2] M.-C. Daniel and D. Astruc, "Gold nanoparticles: assembly, supramolecular chemistry, quantum-size-related properties, and applications toward biology, catalysis, and nanotechnology," Chemical Reviews, vol. 104, no. 1, pp. 293-346, 2004.

[3] Y. Seol, A. E. Carpenter, and T. T. Perkins, "Gold nanoparticles: enhanced optical trapping and sensitivity coupled with significant heating," Optics Letters, vol. 31, no. 16, pp. 2429-2431, 2006.

[4] M. Hu, J. Chen, Z.-Y. Li et al., "Gold nanostructures: engineering their plasmonic properties for biomedical applications," Chemical Society Reviews, vol. 35, no. 11, pp. 1084-1094, 2006. 
[5] A. Azetsu, H. Koga, A. Isogai, and T. Kitaoka, "Synthesis and catalytic features of hybrid metal nanoparticles supported on cellulose nanofibers," Catalysts, vol. 1, no. 1, pp. 83-96, 2011.

[6] T. Premkumar, K. Lee, and K. E. Geckeler, "Shape-tailoring and catalytic function of anisotropic gold nanostructures," Nanoscale Research Letters, vol. 6, article 547, 12 pages, 2011.

[7] H.-L. Jiang, T. Akita, T. Ishida, M. Haruta, and Q. Xu, "Synergistic catalysis of Au@Ag core-shell nanoparticles stabilized on metal-organic framework," Journal of the American Chemical Society, vol. 133, no. 5, pp. 1304-1306, 2011.

[8] R. Narayanan, C. Tabor, and M. A. El-Sayed, "Can the observed changes in the size or shape of a colloidal nanocatalyst reveal the nanocatalysis mechanism type: homogeneous or heterogeneous?" Topics in Catalysis, vol. 48, no. 1-4, pp. 60-74, 2008.

[9] M. A. Mahmoud, R. Narayanan, and M. A. El-Sayed, "Enhancing colloidal metallic nanocatalysis: sharp edges and corners for solid nanoparticles and cage effect for hollow ones," Accounts of Chemical Research, vol. 46, no. 8, pp. 1795-1805, 2013.

[10] M. Chen, H. Kang, Y. Gong, J. Guo, H. Zhang, and R. Liu, "Bacterial cellulose supported gold nanoparticles with excellent catalytic properties," ACS Applied Materials \& Interfaces, vol. 7, no. 39, pp. 21717-21726, 2015.

[11] P. S. Rathore, R. Patidar, T. Shripathi, and S. Thakore, "Magnetically separable core-shell iron oxide@nickel nanoparticles as high-performance recyclable catalysts for chemoselective reduction of nitroaromatics," Catalysis Science and Technology, vol. 5, no. 1, pp. 286-295, 2015.

[12] S. Wunder, F. Polzer, Y. Lu, Y. Mei, and M. Ballauff, "Kinetic analysis of catalytic reduction of 4-nitrophenol by metallic nanoparticles immobilized in spherical polyelectrolyte brushes," The Journal of Physical Chemistry C, vol. 114, no. 19, pp. 8814-8820, 2010.

[13] P. Hervés, M. Pérez-Lorenzo, L. M. Liz-Marzán, J. Dzubiella, Y. Lu, and M. Ballauff, "Catalysis by metallic nanoparticles in aqueous solution: model reactions," Chemical Society Reviews, vol. 41, no. 17, pp. 5577-5587, 2012.

[14] K. Kuroda, T. Ishida, and M. Haruta, "Reduction of 4nitrophenol to 4-aminophenol over Au nanoparticles deposited on PMMA," Journal of Molecular Catalysis A: Chemical, vol. 298, no. 1-2, pp. 7-11, 2009.

[15] S. K. Ghosh, M. Mandal, S. Kundu, S. Nath, and T. Pal, "Bimetallic Pt-Ni nanoparticles can catalyze reduction of aromatic nitro compounds by sodium borohydride in aqueous solution," Applied Catalysis A: General, vol. 268, no. 1-2, pp. 61-66, 2004.

[16] R. W. Scott, O. M. Wilson, S.-K. Oh, E. A. Kenik, R. M. Crooks, and R. W. Scott, "Bimetallic palladium-gold dendrimer-encapsulated catalysts," Journal of the American Chemical Society, vol. 126, no. 47, pp. 15583-15591, 2004.

[17] Z. D. Pozun, S. E. Rodenbusch, E. Keller et al., "A systematic investigation of p-nitrophenol reduction by bimetallic dendrimer encapsulated nanoparticles," Journal of Physical Chemistry C, vol. 117, no. 15, pp. 7598-7604, 2013.

[18] M. Hajfathalian, K. D. Gilroy, A. Yaghoubzade et al., "Photocatalytic enhancements to the reduction of 4-nitrophenol by resonantly excited triangular gold-copper nanostructures," The Journal of Physical Chemistry C, vol. 119, no. 30, pp. 17308-17315, 2015.

[19] N. Pradhan, A. Pal, and T. Pal, "Silver nanoparticle catalyzed reduction of aromatic nitro compounds," Colloids and Surfaces
A: Physicochemical and Engineering Aspects, vol. 196, no. 2-3, pp. 247-257, 2002.

[20] J. F. Corbett, "An historical review of the use of dye precursors in the formulation of commercial oxidation hair dyes," Dyes and Pigments, vol. 41, no. 1-2, pp. 127-136, 1999.

[21] T. Vincent and E. Guibal, "Chitosan-supported palladium catalyst. 3. Influence of experimental parameters on nitrophenol degradation," Langmuir, vol. 19, no. 20, pp. 8475-8483, 2003.

[22] S. Saha, A. Pal, S. Kundu, S. Basu, and T. Pal, "Photochemical green synthesis of calcium-alginate-stabilized $\mathrm{Ag}$ and $\mathrm{Au}$ nanoparticles and their catalytic application to 4-nitrophenol reduction," Langmuir, vol. 26, no. 4, pp. 2885-2893, 2010.

[23] S. Jana, S. K. Ghosh, S. Nath et al., "Synthesis of silver nanoshellcoated cationic polystyrene beads: a solid phase catalyst for the reduction of 4-nitrophenol," Applied Catalysis A: General, vol. 313, no. 1, pp. 41-48, 2006.

[24] M. A. Mahmoud and M. A. El-Sayed, "Time dependence and signs of the shift of the surface plasmon resonance frequency in nanocages elucidate the nanocatalysis mechanism in hollow nanoparticles," Nano Letters, vol. 11, no. 3, pp. 946-953, 2011.

[25] X. Chen, D. Zhao, Y. An et al., "Formation and catalytic activity of spherical composites with surfaces coated with gold nanoparticles," Journal of Colloid and Interface Science, vol. 322, no. 2, pp. 414-420, 2008.

[26] K. S. Shin, J.-Y. Choi, C. S. Park, H. J. Jang, and K. Kim, "Facile synthesis and catalytic application of silver-deposited magnetic nanoparticles," Catalysis Letters, vol. 133, no. 1-2, pp. 1-7, 2009.

[27] K. M. Manesh, A. I. Gopalan, K.-P. Lee, and S. Komathi, "Silver nanoparticles distributed into polyaniline bridged silica network: a functional nanocatalyst having synergistic influence for catalysis," Catalysis Communications, vol. 11, no. 10, pp. 913-918, 2010.

[28] J. Zeng, Q. Zhang, J. Chen, and Y. Xia, "A comparison study of the catalytic properties of Au-based nanocages, nanoboxes, and nanoparticles," Nano Letters, vol. 10, no. 1, pp. 30-35, 2010.

[29] N. Pradhan, A. Pal, and T. Pal, "Catalytic reduction of aromatic nitro compounds by coinage metal nanoparticles," Langmuir, vol. 17, no. 5, pp. 1800-1802, 2001.

[30] A. G. M. Da Silva, T. S. Rodrigues, A. Macedo, R. T. P. Da Silva, and P. H. C. Camargo, "An undergraduate level experiment on the synthesis of Au nanoparticles and their size-dependent optical and catalytic properties," Quimica Nova, vol. 37, no. 10, pp. 1716-1720, 2014.

[31] M. A. Mahmoud, F. Saira, and M. A. El-Sayed, "Experimental evidence for the nanocage effect in catalysis with hollow nanoparticles," Nano Letters, vol. 10, no. 9, pp. 3764-3769, 2010.

[32] W. Gao, L. Ji, L. Li et al., "Bifunctional combined Au- $\mathrm{Fe}_{2} \mathrm{O}_{3}$ nanoparticles for induction of cancer cell-specific apoptosis and real-time imaging," Biomaterials, vol. 33, no. 14, pp. 3710-3718, 2012.

[33] J. Yang, X. Chen, X. Yang, and J. Y. Ying, "Stabilization and compressive strain effect of AuCu core on Pt shell for oxygen reduction reaction," Energy \& Environmental Science, vol. 5, no. 10, pp. 8976-8981, 2012.

[34] E. Lam, S. Hrapovic, E. Majid, J. H. Chong, and J. H. T. Luong, "Catalysis using gold nanoparticles decorated on nanocrystalline cellulose," Nanoscale, vol. 4, no. 3, pp. 997-1002, 2012. 
[35] Y. Yao, Y. Sun, Y. Han, and C. Yan, "Preparation of resorcinarene-functionalized gold nanoparticles and their catalytic activities for reduction of aromatic nitro compounds," Chinese Journal of Chemistry, vol. 28, no. 5, pp. 705-712, 2010.

[36] C.-W. Yang, K. Chanda, P.-H. Lin, Y.-N. Wang, C.-W. Liao, and M. H. Huang, "Fabrication of Au-Pd core-shell heterostructures with systematic shape evolution using octahedral nanocrystal cores and their catalytic activity," Journal of the American Chemical Society, vol. 133, no. 49, pp. 19993-20000, 2011. 

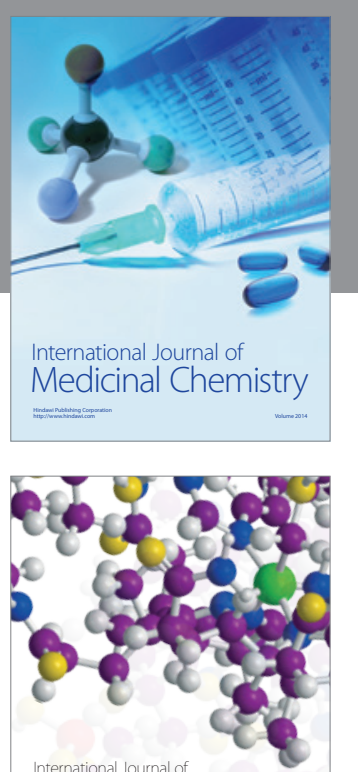

Carbohydrate Chemistry

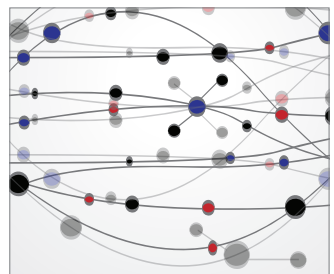

The Scientific World Journal
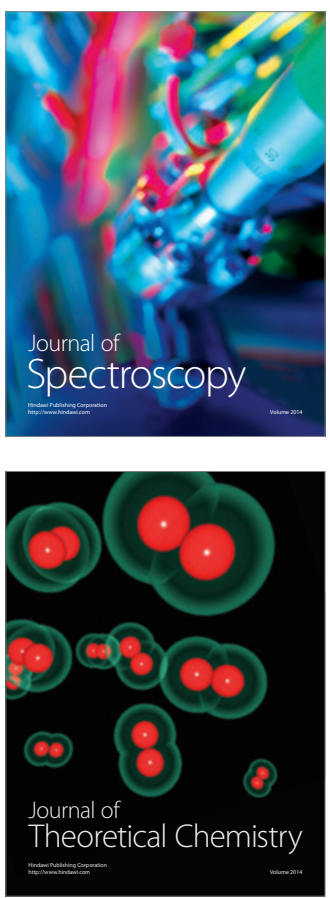
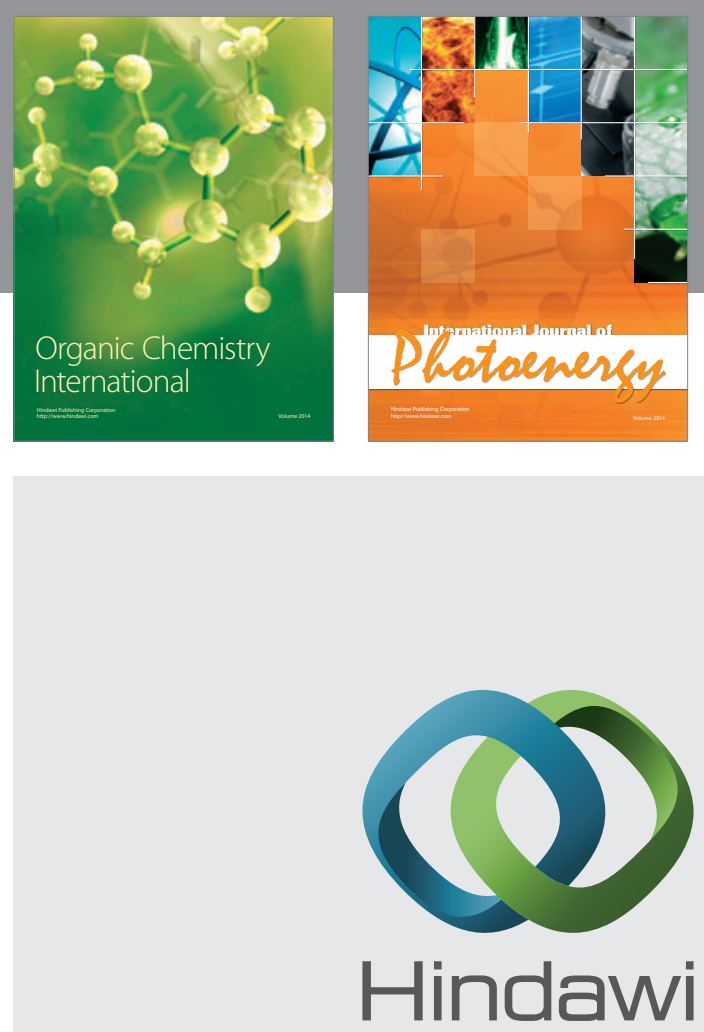

Submit your manuscripts at

http://www.hindawi.com

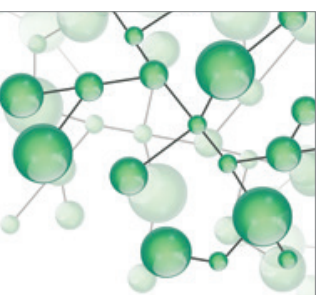

International Journal of

Inorganic Chemistry

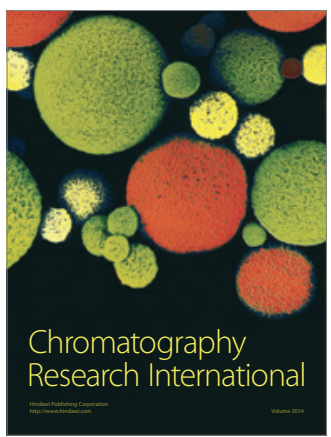

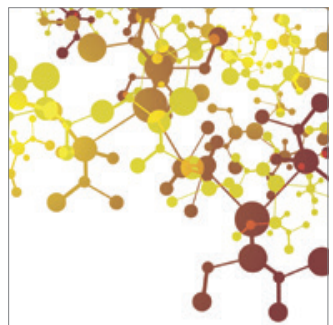

Applied Chemistry
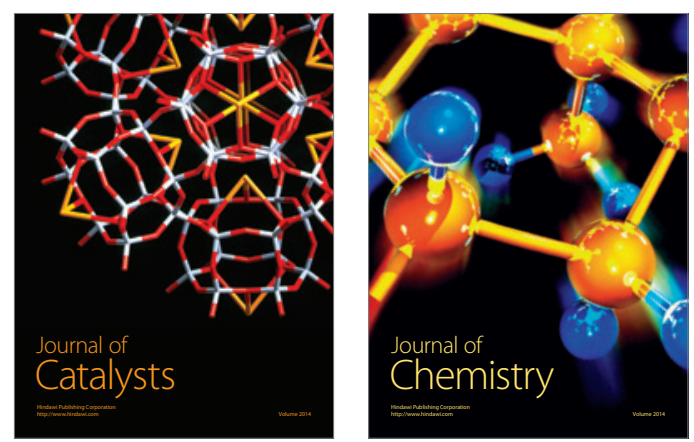
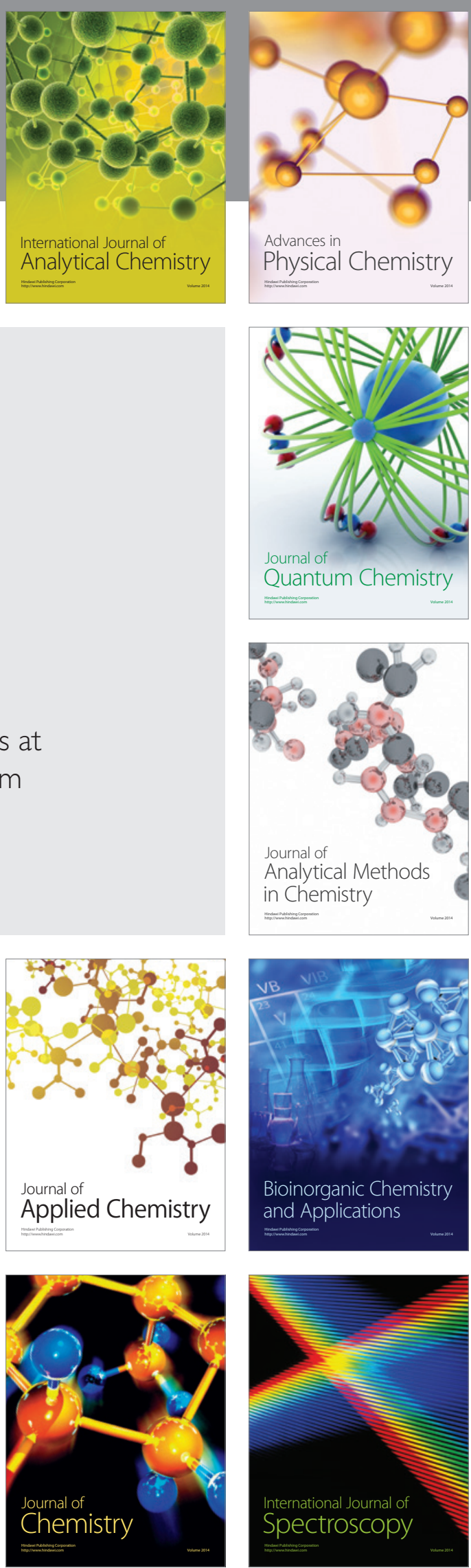